\title{
27
}

\section{Using Comprehensive Mapping and Database Management to Improve Modeling of Urban Sewer Systems}

Joe Hoffman and David Crawford

The City of Portland, Oregon, Bureau of Environmental Services (BES) and a consultant team are currently evaluating alternatives to reduce the potential for basement flooding in the Holladay, Stark, and Sullivan combined sewer basins. To assist with hydraulic analysis for this project, BES developed a detailed SWMM model of the basin using a suite of geographic information system (GIS) and database tools to automate many of the steps for data extraction, variable assignments, and model building. The detailed model contains essentially all of the pipes in the collection system and utilizes surface water and direct connection subcatchments to place runoff into the system in the correct location. The subcatchments are small, generally representing one city block, therefore much of the uncertainty associated with lumping RUNOFF parameters is eliminated. A virtual raingage program was used during model calibration to triangulate between real raingages and create a separate rainfall interface file for each quartersection in the model. The detailed GIS approach and virtual raingage produced model results that correlated very well with flow monitoring data. A GIS tool was developed to analyze flooding of individual parcels by overlaying modeled hydraulic grade lines with estimated finished floor elevations obtained from a digital terrain model (DTM). The detailed SWMM model shows that much of the system capacity problems are in the local areas at the upstream ends of the system and that the local collection system tends to hold water back from the downstream trunklines in the system. This better understanding of where system capacity constraints occur allows

Hoffman, J. and D. Crawford. 2001. "Using Comprehensive Mapping and Database Management to Improve Modeling of Urban Sewer Systems." Journal of Water Management Modeling R207-27. doi: 10.14796/JWMM.R207-27.

(C) CHI 2001 www.chijournal.org ISSN: 2292-6062 (Formerly in Models and applications to Urban Water Systems. ISBN: 0-9683681-4-X) 
BES a top down view of the basin during analysis. Local inflow control alternatives are considered first and pipe upsizing along with passing the problem downstream is the second alternative.

\subsection{Introduction}

Approximately half of the City of Portland, Oregon is sewered through a combined sewer system with the BES charged with providing adequate drainage infrastructure. BES and a consultant team are currently evaluating alternatives to reduce basement flooding in the Holladay, Stark, and Sullivan (HOSTSU) combined sewer basins.

The HOSTSU basins cover an area of 4,740 acres (1,927 ha) and contain approximately 175 miles $(281 \mathrm{~km})$ of pipe from 6 inches $(152 \mathrm{~mm})$ to 78 inches $(1,980 \mathrm{~mm})$ in diameter, as shown in Figure 27.1.

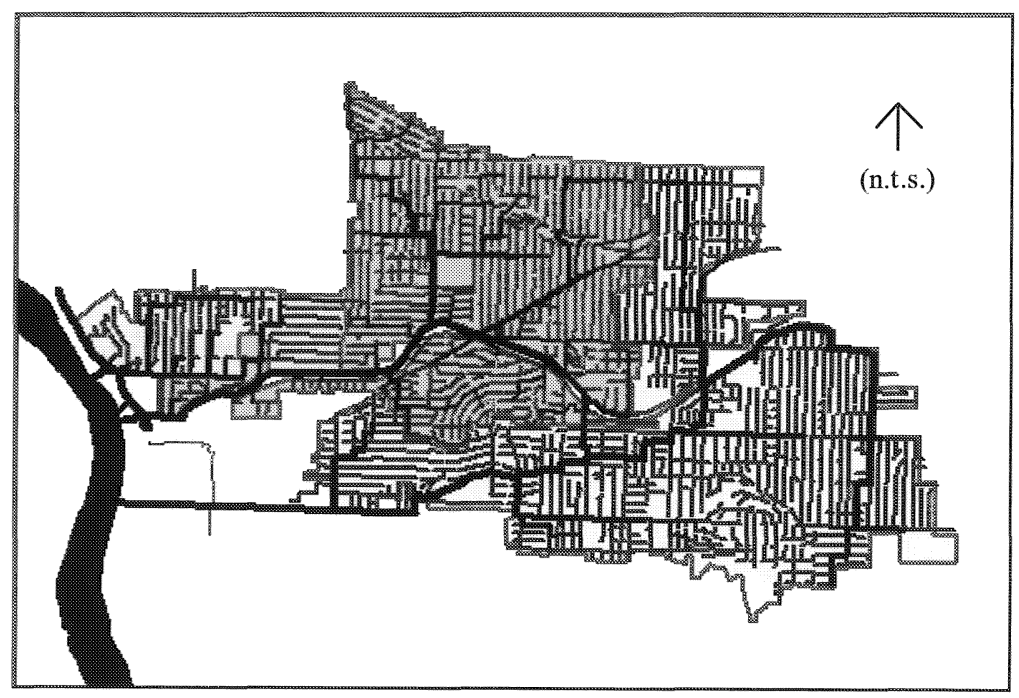

Figure 27.1 Study basin and pipe network.

There have been 648 basement flooding complaints in the basins and 306 positive responses to a survey that was mailed to the public at the beginning of the project, see Figure 27.2. Many pipes experience excessive surcharging and street flooding during the 25-y design storm. Much of the basement flooding is in local areas at the upstream ends of the system. 


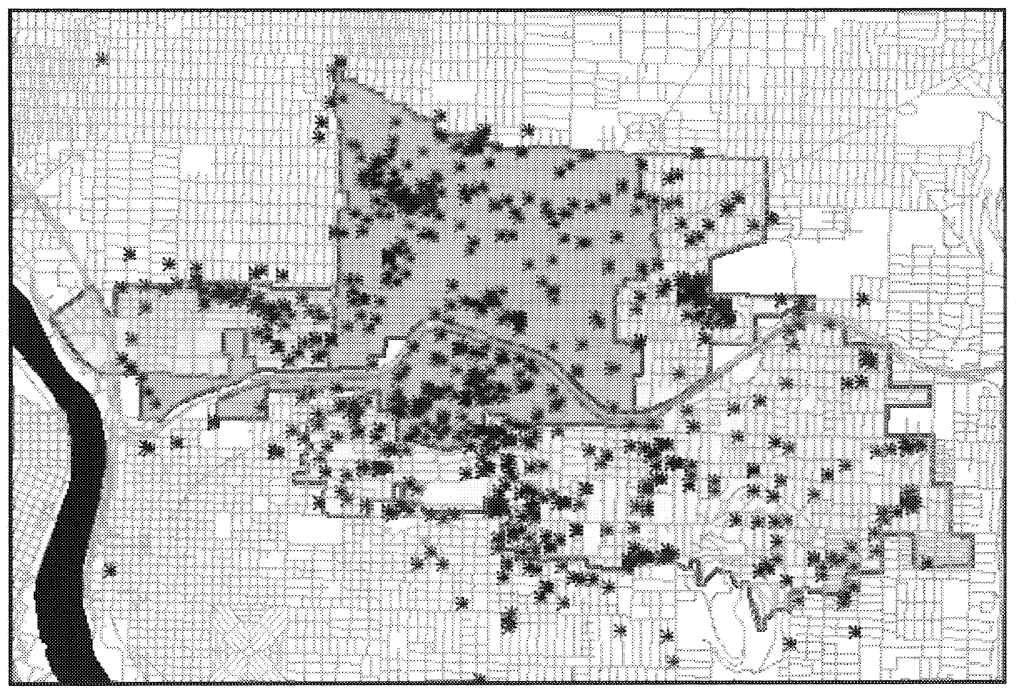

Figure 27.2 Historical basement flooding complaints.

BES installed a number of infiltration sumps to reduce combined sewer overflows and basement flooding as shown in Figure 27.3. Storm water runoff is routed from street inlets to a sedimentation manhole and then to the sump where it infiltrates into the ground. Additional sumps are planned for the southeast portion of the basin.

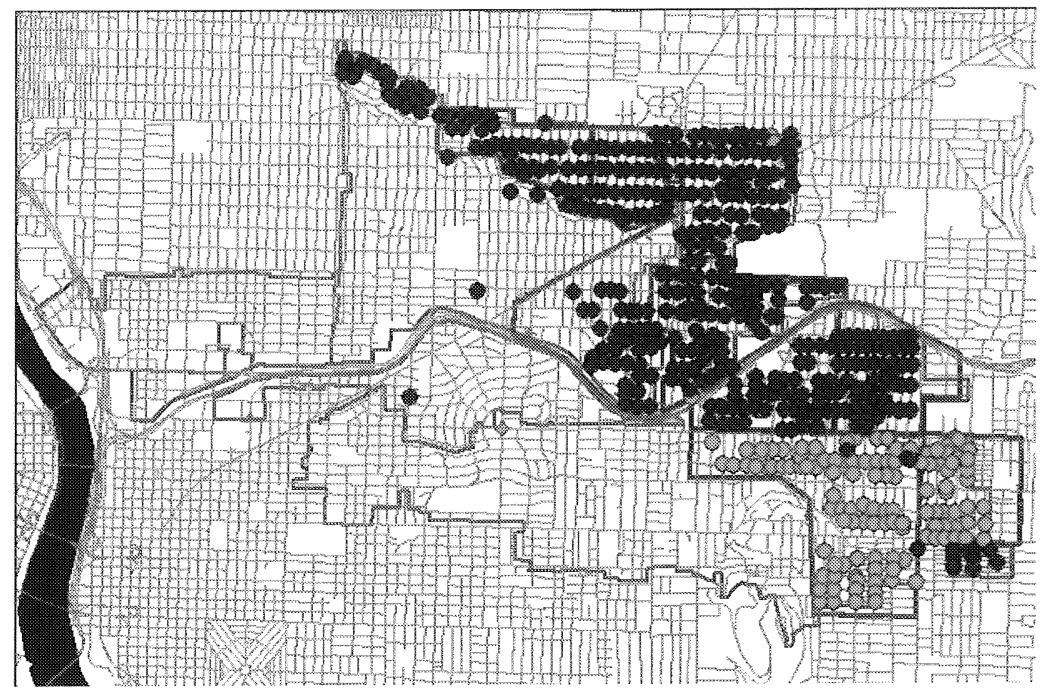

Figure 27.3 Existing and future sump locations. 
BES created detailed SWMM RUNOFF and EXTRAN models of the combined sewer system to analyze local flooding problems. The model contains essentially every combined sewer pipe in the basin and utilizes two subcatchment definitions to place water into the system in the correct location. Surface water subcatchments are delineated for the areas that flow into the sewer through street inlets in the public right-of-way. Direct connection subcatchments are delineated for the areas that contribute sanitary and stormwater drainage to the sewer through service laterals. The subcatchments are small, generally representing one city block, therefore much of the uncertainty associated with lumping RUNOFF parameters is eliminated. The model calibrated very well with existing flow monitoring data and proved to be a very useful tool for determining flooding risk and analyzing alternatives.

The following section discusses the construction of the model with GIS data. Subsequent sections describe model calibration, flooding risk and alternatives analysis, and conclusions.

\subsection{Model Construction}

Detailed SWMM RUNOFF and EXTRAN models were constructed for the HOSTSU basin to allow analysis of local flooding. The models were constructed from facility maps and photogrammetric data with the use of a MapInfo GIS, and a Microsoft Access database. Construction of the RUNOFF and EXTRAN models is discussed below.

\subsubsection{RUNOFF}

The RUNOFF model uses two subcatchment definitions to place water into the system in the correct location. Direct connection subcatchments are defined as the areas that contribute sanitary and stormwater drainage to the sewer through service laterals. Surface water subcatchments are defined as the areas that flow into the sewer through street inlets in the public right-of-way. These subcatchment definitions place water into the model in the correct location, which is extremely important when modeling local pipes. For example, surface water introduced into a small pipe too early will cause it to surcharge. If water from direct connections is input too late it will cause "dry" pipes. Each of these subcatchments is discussed in more detail below, along with some of the GIS queries used to characterize the physical parameters of the subcatchments. 


\section{Direct Connection Subcatchments}

Direct connection subcatchments consist of the impervious area of each taxlot that is directly connected to the sewer through laterals as shown in Figure 27.4. Direct connection subcatchments are delineated for each pipe with service laterals. They contain only the impervious area of a taxlot and are therefore $100 \%$ impervious. It is assumed that the pervious areas of the taxlots drain to the street and are therefore included in the surface watersubcatchments; although this is generally the case for single family taxlots it may not always be the case for commercial areas.

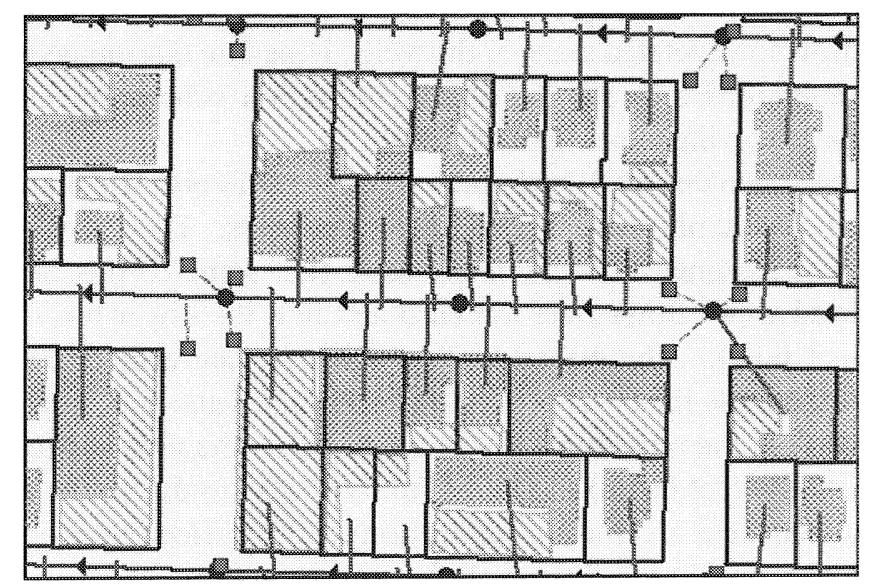

Figure 27.4 Direct connection subcatchments.

Delineation. The connected impervious areas of each taxlot are the true boundaries of the direct connection subcatchments, but the taxlot object itself is used in the GIS to aggregate the impervious areas.

A virtual sewer lateral is used as a pointer object in the GIS to indicate which pipe serves each taxlot. Taxlots draining to multiple sewers were divided into smaller areas, each with its own lateral pointer.

The lateral pointers were necessary because the City's existing lateral maps were not sufficient to indicate which pipe served each taxlot (i.e. they did not touch the taxlot nor did they contain attribute data to indicate which parcel they served). The laterals were drawn automatically using the GIS to connect the centroid of each building to the closest point on the main sewer for each of the 19,000 parcels in the basin. Some manual adjustment of the laterals was necessary to ensure that each taxlot was connected properly. When the lateral pointers were complete, the GIS was used to write the model segment ID of each sewer line into the lateral pointers that it intersected. Subsequently, the 
segment ID was passed from the lateral pointer to the taxlot that it intersected. The segment ID was used to sum the impervious areas of the taxlots connected to each pipe to create a direct connection subcatchment. Runoff from the direct connection subcatchments is typically inserted into the model at the upstream manhole of each segment.

Impervious Percent. The impervious roof and parking areas for each parcel were obtained from photogrammetric maps of the City. The model was based on impervious areas only. No impervious area assumptions were made based on landuse.

Some of the roofs and parking lots are disconnected from the service lateral and flow to vegetated areas or drywells. Based on disconnection survey data, the impervious area for the direct connection subcatchments was set assuming the following existing conditions:

1. Twenty percent $(20 \%)$ of single family roofs are disconnected from the combined sewer in unsumped areas. This disconnection is assumed to be $70 \%$ effective (i.e. some of the disconnected water flows over the curb and into the sewer through a street inlet). The effective disconnection rate accounting for both of these factors is $14 \%$ with the surface water subcatchment receiving the remaining $6 \%$ as discussed in the next section.

2. Thirty percent $(30 \%)$ of single family roofs are disconnected in sumped areas and this disconnection is $100 \%$ effective since any water reaching the street will flow into a sump.

3 . Twenty percent $(20 \%)$ of commercial roofs and parking lots are disconnected to a drywell in sumped areas.

The following equations use the existing impervious areas and assumed disconnection rates to calculate the impervious area, subcatchment area, and impervious percentage of each parcel that is directly connected to the sewer.

Impervious Area $=$

((Area Taxlot -Sumped Area)/Area Taxlot) x (0.8 x Area Single Family Roofs + Area Commercial Roofs + Area Parking) +

Sumped Area/Area Taxlot) x (0.7x Area Single Family Roofs $+0.8 x$

(Area Commercial Roofs + Area Parking))

where the first part of the equation pertains to the unsumped portion of a taxlot and the second part of the equation refers to the sumped portion of the taxlot

Subcatchment Area $=$ Impervious Area

Impervious Percent $=100$

The database is used to sum the impervious area of the parcels for each pipe and the flows are placed into the model at the upstream node. 
Width. RUNOFF requires a modeling parameter width to indicate the shape or flow path of the subcatchment.

The width of the direct connection subcatchment was calculated as:

Width $=$ Area/Flow Length

Flow Length was assumed to be:

Flow Length $=25$ feet of overland flow + subcatchment pipe length 6

The equation for width generally attempts to discount the channelized flow in the pipe and make the direct connection subcatchments concentrate faster then the surface water subcatchments. The width parameter should not have a great influence on model results for these relatively small subcatchments, since the time of concentration of the subcatchment is less then the duration of most storms.

Slope. The slope of all direct connection subcatchments is assumed to be $6 \%$, being a combination of commercial and single family roof slopes and parking lot slopes. As an additional refinement we may vary slope by parcel landuse in the future.

\section{Surface Water Subcatchments.}

Surface Water Subcatchments are delineated for each group of inlets as shown in Figure 27.5. The street pavement and pervious areas from the parcels are included in the surface water subcatchments. However, they do not include the impervious areas of each taxlot that are connected to the sewer through service laterals. These areas are included in the direct connection subcatchments as discussed in the previous section. Delineation of subcatchments and determination of impervious area, width, and slope with the GIS are discussed below.

Delineation. The surface water subcatchments were delineated with the aid of a DTM. The DTM was created from contour maps of the project area using Vertical Mapper, a third party application for Mapinfo. Slope and aspect grids were created from the DTM. The aspect grids show the direction that each grid drains expressed as degrees from north. A vector representation of the aspect was created for each grid to assist with delineation of the surface water subcatchments. The aspect arrows are shown in Figure 27.5. We hope to delineate the surface water subcatchments automatically from the DTM. We feel that a more accurate DTM will be required to allow automatic delineation in urban terrain, particularly in the streets where particular attention must be given to insure that no interpolation occurs between spot elevation on opposite sides of the street causing virtual dams in the surface. 


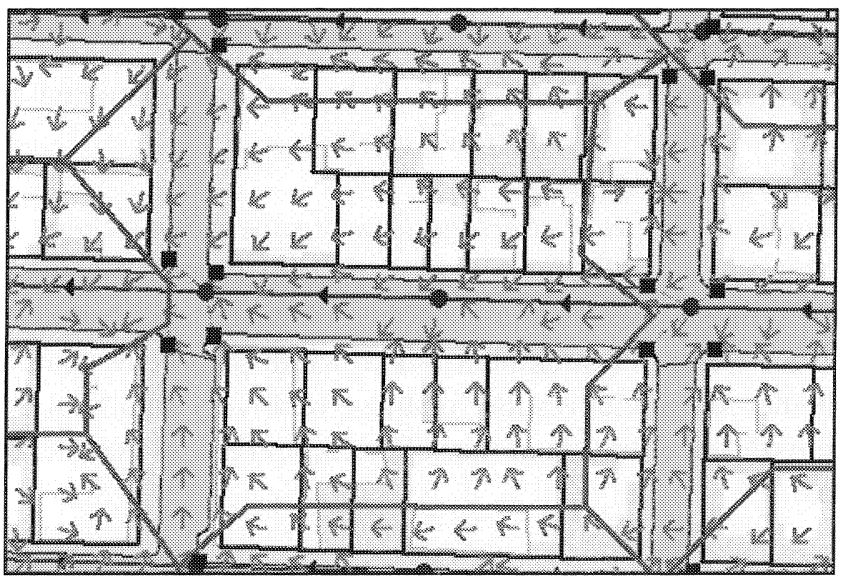

Figure 27.5 Surface water subcatchment.

Impervious Percent. Surface water subcatchments with infiltration sumps that were installed prior to the date being modeled were given a data flag so that they would not be included in the SWMM RUNOFF model. This assumes that $100 \%$ of the runoff was taken by the sump and removed from the combined sewer system.

Impervious Area $=$ Area Street Pavement + Inefficient Portion of Disconnected Single Family House = Area Pavement $+0.06 *$ Area Single Family Roof

Subcatchment Area $=$ Total Area - Directly Connected Impervious Areas

= Total Area - 0.8*Area Single Family Roof - Area Commercial Roof Area Parking

Impervious Percent $=($ Impervious Area $/$ Subcatchment Area $) \times 100$

Width. The width of the surface water subcatchments was calculated by dividing the area of each subcatchment by the length of overland flow. The length of overland flow was assumed to be 150 feet $(46 \mathrm{~m})$ of flow from the back of a lot to the street plus the distance from the farthest pavement point in the subcatchment to the surface water inlet. The distance from the farthest pavement point was determined with the GIS by using a routine to create points at 5 foot $(1.5 \mathrm{~m})$ intervals along a street centerline map and querying for the farthest point within the subcatchment.

Slope. The slope of each surface water subcatchment was calculated from the slope grid. The average slope of all of the 40 foot $(12 \mathrm{~m})$ grids within the subcatchment was used as the subcatchment slope. 


\subsubsection{EXTRAN}

The EXTRAN model was constructed with a database from BES facility maps. The BES facility maps have been created over the years from "as-builts", but the maps were far from perfect and required data conditioning to insure connectivity and proper pipe attributes such as length, diameter, and invert elevations. The maps contained a node numbering scheme that was used by maintenance personnel.

The connectivity of the node numbers was checked in the GIS using a routine that traversed the pipe network using the node and segment connectivity. The routine prompts the user to select an upstream pipe and a downstream pipe, and then attempts to traverse from one segment to the other, organizing the pipes in order from upstream to downstream, and assigning a reach number to each group of pipes to assist with interpolation of inverts. The inverts of nodes were checked to make sure that pipes had positive slopes and at least one outgoing invert was lower than the incoming inverts. Missing inverts were commonly interpolated from upstream and downstream nodes using Microsoft Access $($ queries, or researched from As-built drawings. All inverts were given a data flag to indicate their source.

Once the facility maps were corrected, a 3,813 segment EXTRAN model of the whole basin was constructed by selecting the pipes in the GIS and setting an Extran flag to indicate they were to be included in the model. Average sanitary baseflow was inserted in the model by joining the water billing records to the address of each parcel. The lateral pointers were then used to group the flows for each pipe and to initialize the average baseflow at the upstream node. Hourly diurnal factors were applied to the baseflow. A database query is used to create an EXTRAN deck from the selected pipes. The RUNOFF datafile is created from the subcatchment database by selecting subcatchments that drain to the EXTRAN nodes.

Because the direct connection subcatchments are delineated for every pipe with laterals and the surface water subcatchments are delineated for each group of inlets, the modeling group maintains only one set of subcatchment data from which many different models can be constructed to meet the requirements of multiple users. As described above, the user simply selects the pipes to be included in the model, taking care to include all upstream pipes, and then builds the EXTRAN and RUNOFF datafiles without concern that the RUNOFF subcatchments may not be delineated properly for the pipe selection. This is a departure from the traditional method of lumping subcatchments to design points where the user must take care not to select a pipe above the last design point, or must revise the subcatchment database if it is necessary to model an upstream pipe. 
It may be possible to reduce the runtime of the model for large basins by including some of the pipes in the upper reaches of the basin in the RUNOFF model without significantly changing the calibration of the model. There is some danger in this approach because RUNOFF will tend to hold back flow that EXTRAN will push through. One possibility for overcoming this problem would be to give the RUNOFF pipe a slope equal to the maximum slope of the hydraulic grade line as determined in EXTRAN for a surcharged system. We have not tried simplifying the model in this manner, as EXTRAN runs the model with our $6 \mathrm{~h}$ design storm, at $10 \mathrm{~s}$ time steps, on a $600 \mathrm{MHz}$ computer, in approximately 20 minutes. We may be forced to perform this simplification if we run long-term simulations with historical storms to evaluate the performance of our alternatives.

The City is in the process of developing a citywide GIS. It is our hope that we can develop a data sharing process where the pipe network, taxlots, impervious areas, and lateral maps will be updated by others as they perform their work, and that this model definition will allow us to quickly update the model and share detailed flow data in return.

\subsection{Calibration Results}

The model was calibrated using historical rainfall and flow monitoring data. The raingages and flow monitors that were used in the calibration are discussed in the next section, followed by the calibration results.

\subsubsection{Raingages and Flow Monitors}

Flow monitoring and raingage locations that were used for the project are shown in Figure 27.6. A computer program was used to create a virtual raingage for each quartersection in the basins. The program uses rainfall data from active monitors and calculates a rainfall intensity for each quartersection, thereby simulating the aerial distribution of the rainfall event in the RUNOFF Model as shown in Figure 27.7.

Rainfall values were determined for each quartersection by a weighted average of the rain at the three nearest raingages using the reciprocal distancesquared method:

$$
[\text { Virtual Ra infall }]=\frac{\left[\frac{R A I N}{D I S T^{2}}\right]_{\text {Gagel }}+\left[\frac{R A I N}{D I S T^{2}}\right]_{\text {Gage } 2}+\left[\frac{R A I N}{D I S T^{2}}\right]_{\text {Gage3 } 3}}{\left[\frac{1}{D I S T^{2}}\right]_{\text {Gage1 }}+\left[\frac{1}{D I S T^{2}}\right]_{\text {Gage } 2}+\left[\frac{1}{D I S T^{2}}\right]_{\text {Gage3 } 3}}
$$




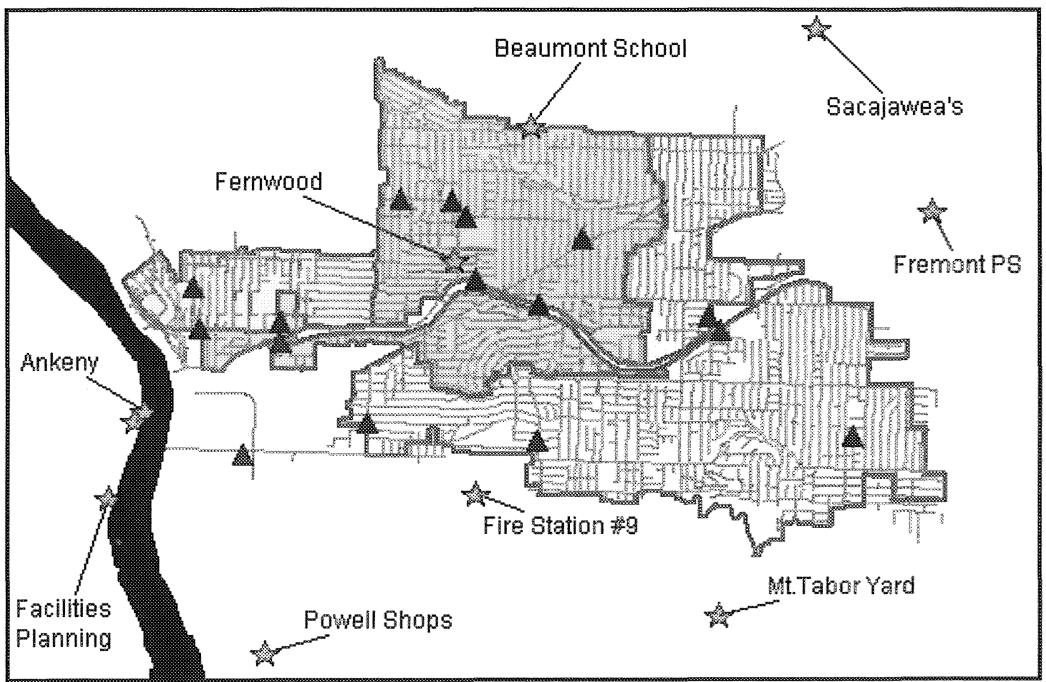

Figure 27.6 Raingage and flow monitor locations.

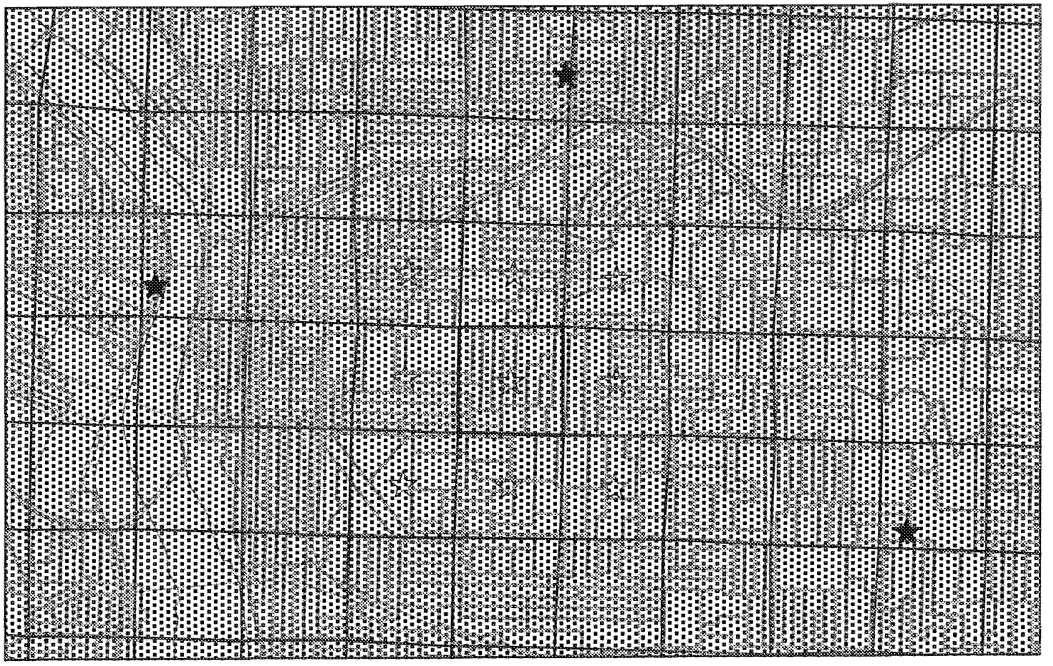

Figure 27.7 Virtual raingage.

where:

$R A I N=$ rainfall intensity at real gage, $\mathrm{in} / \mathrm{h}$, and

$D I S T=$ distance from centroid of quartersection to raingage, $\mathrm{ft}$ 


\subsubsection{Calibration Results}

The model calibrated very well with the flow monitors on the first try and required little calibration. The few changes necessary to provide a calibrated model were mainly related to how basins were assumed connected to the collection system. The assumed roof disconnection rates were not revised. The model calibrated very well in all areas from small to large. Also, the calibration was very good for all storms used to calibrate the model, which indicates that the rainfall is being distributed correctly within the basin, even for smaller storm cells.

Figure 27.8 shows the metered and modeled depth of flow, during a December 27, 1998 storm, for a flow monitor located at 27th and Knott. The drainage area contributing to this point is approximately 28 acres $(11 \mathrm{ha})$. The peak modeled flow rate corresponding to a depth of 7.2 inches $(183 \mathrm{~mm})$ is approximately $3.3 \mathrm{cfs}$. The meter and model results compare quite favorably for this relatively small area, except at depths below 2 inches $(51 \mathrm{~mm})$. The monitor cannot accurately measure depths below approximately 2 inches due to the size of the depth and velocity sensor of the monitor.

Figure 27.9 shows the metered and modeled results, during the same storm, for a flow monitor located at 10th and Stark. The drainage area

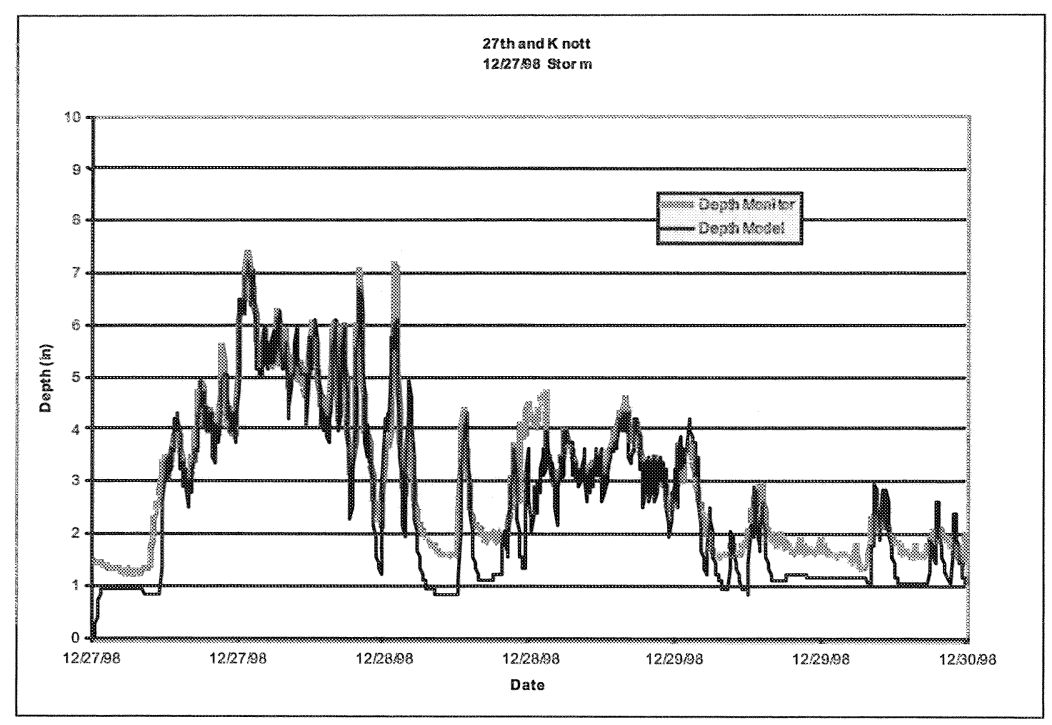

Figure 27.8 Model depth of flow versus monitor at 27th and Knott. 
contributing to this point is approximately 2340 acres $(951$ ha). The peak modeled flow rate corresponding to a depth of 22 inches $(559 \mathrm{~mm})$ is approximately $170 \mathrm{cfs}$. The meter and model results compare quite favorably for this relatively large area.

It is interesting to note the difference in response times shown in the two hydrographs. As expected, the small local area shows a much quicker and more detailed response to the storm, while the hydrograph of the larger area changes more gradually.

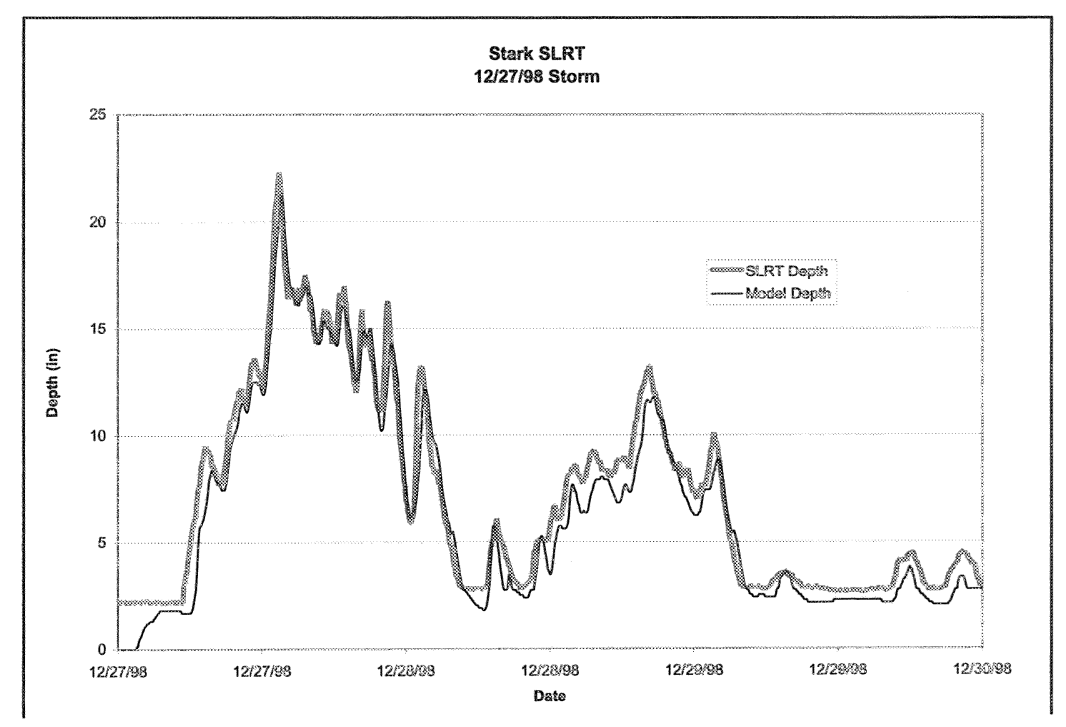

Figure 27.9 Model depth of flow versus monitor at Stark and 10th.

\subsection{Basement Flooding Risk and Alternatives Analysis}

A GIS analysis was performed to establish basement flooding risk for the existing and future condition of the basins. Pipe upsizing and inflow reduction alternatives are being examined to reduce flooding in these areas. The methods used to determine basement flooding risk are described in the next section. The subsequent section discusses the approach the City is taking toward alternatives analysis. 


\subsubsection{Basement Flooding Risk}

The model definition allows the basement flooding risk to be determined for individual parcels for a particular design storm or historical event, and for selected control alternatives. The process used to determine flooding risk is as follows:

1. Tax assessor's data is utilized to determine houses with basements.

2. An estimated first floor elevation is determined for each building by querying the DTM to determine the maximum grid elevation within each house (i.e. elevations are created within each house when the DTM is created from contours and spot elevations around the house) then adding 3 feet $(0.9 \mathrm{~m})$ to account for the foundation of the house and floor joists. See Figure 27.10.

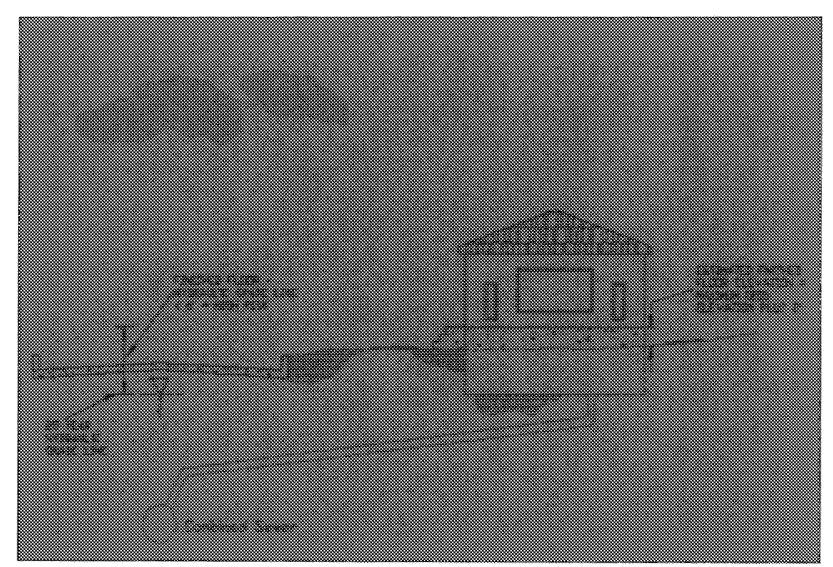

Figure 27.10 Comparing modeled HGL to estimated finished floor.

3. HGL elevations are determined for each lateral pointer with the use of a GIS tool that interpolates between the HGLs determined at the manholes by the model. The interpolated HGL is compared to the estimated finished floor to determine flooding risk assuming the basement floor is 8 feet $(2.4 \mathrm{~m})$ below the finished floor. Taxlots with differences of 0 to 6 feet $(0-1.8 \mathrm{~m})$ are deemed high risk; 6 to 8 feet $(1.8-2.4 \mathrm{~m})$ medium risk; 8 to 10 feet $(2.4-2.8$ $\mathrm{m})$ some risk; and 10 feet or greater low risk. The results are thematically mapped (colored by ranges) in the GIS.

Figure 27.11 shows an example flooding risk map and historical flooding for a portion of the Sullivan Basin. Determining risk in this manner allows a quantitative determination of the number of properties in a basin that will flood 


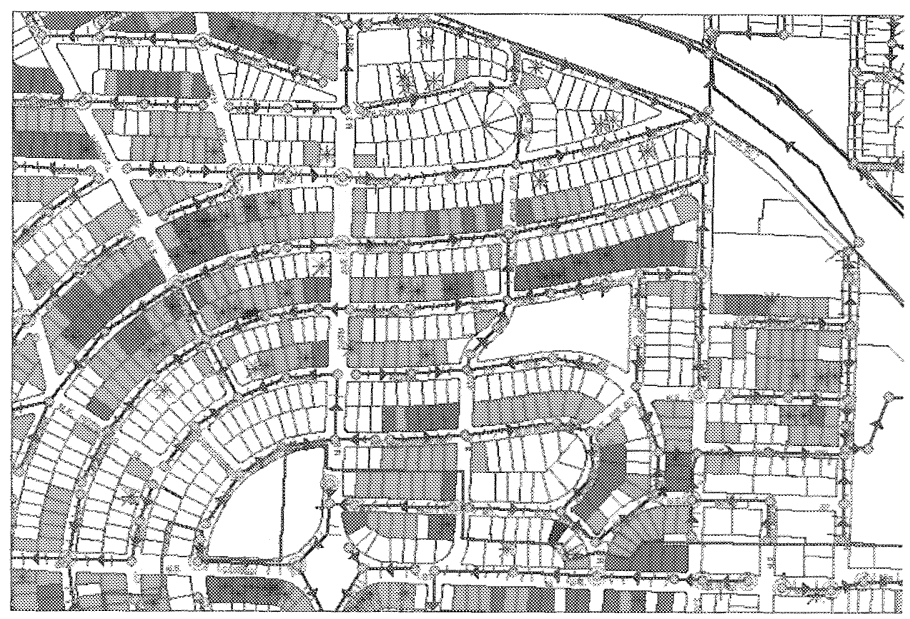

Figure 27.11 Thematic map showing flooding risk (darker colour: higher risk) and historical complaints (star).

for a given design storm, in a manner that is easy to interpret graphically. Of course, this method is limited by the accuracy to which the basement elevation can be determined from the DTM. However, the results compare favorably with historical flooding complaints and this method will give better results than comparing the hydraulic grade line to the elevation of the street surface, since the elevation of houses in Portland may vary substantially up or down from the elevation of the street.

As, shown in Figure 27.11 the flooding risk analysis does not always agree with historical complaints. In some cases the analysis predicts flooding where no complaints have occurred, which might be explained by the fact that many people do not report flooding, or possibly that a storm of the magnitude of the design storm has not occurred in that area. Historical flooding that is not substantiated by the risk analysis may have been solved by a system upgrade that occurred after the flooding, the flooding may have been caused by a larger storm event than the design storm, or by a blockage in the pipe. The condition of the pipes is checked in areas where no other explanation for flooding seems valid. In all cases where there are discrepancies between the model and historical complaints, the model is checked to determine if it appears to correctly represent the area.

The basement flooding risk analysis is also performed after each alternative is modeled to determine the effect of the alternative on flooding. Storms of different recurrence intervals are modeled to determine the sensitivity of areas toward flooding. The most sensitive areas will be given a higher priority when improvements are scheduled. 


\subsubsection{Alternatives Analysis}

Classic approaches to basement flooding usually entail resizing pipes or controlling inflow to the system. For the HOSTSU project a variety of alternatives have been evaluated ranging from a complete replacement of pipes to a blend of "green" solutions and strategic storage and pipe replacements. Alleviating the flooding through a total pipe replacement scheme would require approximately 47 miles $(76 \mathrm{~km})$ of pipes ranging in diameter from 12-inch to 10 -feet $(0.3-3.0 \mathrm{~m})$ with a total cost of about US\$66 million.

Green solutions include an aggressive roof drain disconnection program that encourages homeowners to disconnect roof drains from the combined sewer. Increasing roof drain disconnections from $20 \%$ to $51 \%$ in un-sumped areas reduced the number of high-risk properties from 2630 to 1462 or from about $14 \%$ of the total properties to about $8 \%$. The percent of properties with low risk is increased from about $68 \%$ to $80 \%$ of the total properties in the basins. Table 27.1 shows the change in flooding risk between the future basin condition and the future condition with the $51 \%$ roof drain disconnection alternative. The approximate cost of roof drain disconnection per property is about US $\$ 500$.

Table 27.1 Change in basement flooding risk - existing and roof drain disconnection program.

\begin{tabular}{lcccc}
\multicolumn{1}{c}{ Flooding Risk } & Delta Finished & \multicolumn{3}{c}{ Alternative } \\
\hline \multicolumn{1}{c}{ Risk } & $\begin{array}{c}\text { Floor and HGL } \\
(\mathrm{ft})\end{array}$ & Future Basin & $\begin{array}{c}\text { Roof Drain } \\
\text { Disconnection }\end{array}$ & Change \\
\hline High Risk & $0-6$ & 2630 & 1462 & -1168 \\
At Risk & $6-8$ & 1749 & 1088 & -661 \\
Some Risk & $8-10$ & 1758 & 1252 & -506 \\
Low Risk & $>10$ & 12909 & 15244 & 2335 \\
\hline
\end{tabular}

In addition to roof drains, BES is pursuing other inflow control projects that target pockets of flooding risk in local areas. For example the local area shown in Figure 27.11 and Figure 27.12 has a history of flooding, and is identified by the model as a problem area.

To solve the problem a series of pipe replacements could be proposed. A local pipe replacement would convey the problem downstream which in turn would trigger additional pipe replacements as shown in Figure 27.12. These types of sewer replacement projects are typical of the whole project area. As an alternative, a local project that targets the root cause of the problems can be proposed. In this case there is a large impervious area (school playground and 


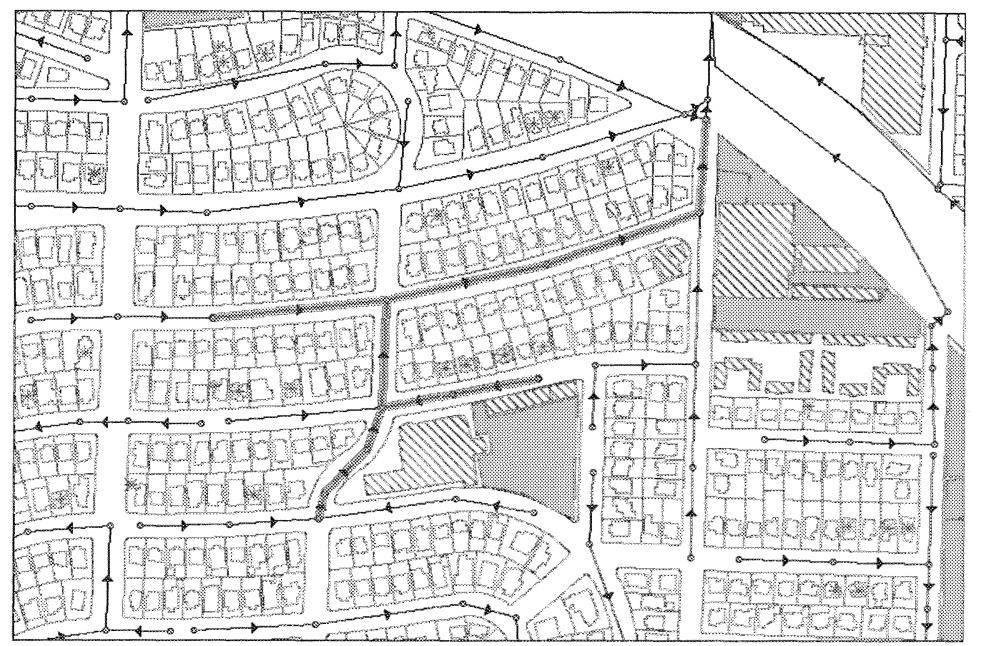

Figure 27.12 Local system upgrades versus green solution.

parking area) at the upstream end of the problem area. The high runoff rate from this relatively large impervious area greatly exceeds the local pipe capacity and hence causes flooding into basements.

Opportunities to control the runoff from the impervious area include construction of a bio-swale for infiltration and peak flow control, disconnection of the impervious area to a sump (if soil infiltration capacity is adequate), and local underground storage pipes. The cost of the series of pipe replacements is the benchmark against which local green projects are measured. Institutional issues concerning construction and maintenance of green solutions on private property are important considerations in the evaluation. A series of pilot green solution projects will be recommended to allow BES to evaluate the performance of green solutions and to work through some of these institutional issues.

\subsection{Conclusions}

The following sections contain conclusions concerning model accuracy, model definition, and basement flooding risk and alternatives analysis.

\subsubsection{Model Accuracy}

Time spent building a detailed model with accurate physical parameters eliminates many of the uncertainties associated with lumping parameters and pays off with a consistently accurate model with less calibration effort required. 
In effect this process creates a model which is more explicit and less of a theoretical abstraction.

It is possible to get good results from a lumped model, however the calibration required to determine the storage and routing of the lumped basin is more difficult and is not necessary in this age of faster computers. If speed is an issue in very large systems or for long simulations, the smaller pipes of the system can be included in the RUNOFF block, perhaps with a steeper pipe slope to simulate surcharging, although we have not tried this to date .

Virtual raingages provide a more accurate method of distributing rainfall over a large basin than selecting one gage to represent the basin.

\subsubsection{Advantages of Model Definition}

Surface water and direct connection subcatchments allow local areas to be modeled accurately by placing water into the system in the correct location. We also believe that these subcatchment definitions make it easier to model streets with parallel pipes and partially separated areas because they allow the user to easily control which pipe a surface water or direct connection subcatchment flows to. Similarly, the subcatchment definitions make it easy to model inflow control alternatives because they do not lump the water from different sources. For instance, if an alternative is evaluated to route street inlets to infiltration sumps the appropriate surface water subcatchments can simply be eliminated from the RUNOFF deck. Onsite detention or roof disconnection can be evaluated using the direct connection subcatchments.

Although the model is more detailed than traditional lumped models, in many ways it is actually easier to construct and maintain with the GIS. This is mainly due to the fact that the subcatchments are relatively small so their width and slope parameters are easy to characterize in the GIS. Also, since the subcatchments are delineated as a type of finite element (i.e. to every group of inlets and to every pipe with service laterals), the modeling group requires only one set of subcatchment data to build multiple models. A model can be built for any area simply by selecting the pipes to be modeled in the GIS and then matching the appropriate subcatchments to the pipes in the database.

\subsubsection{Advantages of Determining Flooding Risk and for Alternatives Analysis}

Performing a flooding risk analysis allows problem areas to be identified for existing and future basin conditions and for different flooding control alternatives. The risk analysis allows the flooding problem to be expressed in terms of basements at risk from a particular storm event, instead of counting historical 
complaints, which were caused by events of different intensities and durations. A worse but common procedure is to express flooding problems in terms of the number of surcharged pipes in a basin without even venturing a guess as to how many basements are flooding. Basements are our primary concern. Surcharged pipes are only of concern if the surcharging is excessive for the pipe material or if street flooding is occurring. Creating thematic maps of basement flooding risk makes the flooding problems and solutions very visible to the design team, City management, and our customers.

The detailed SWMM model shows that many of the flooding problems are caused by capacity constraints in the local areas at the upstream ends of the system. The small pipes in these areas really hold water back from the larger downstream trunk lines. This allows a top down perspective of the basin during alternatives analysis where a choice is made between solving the local problems with inflow control or moving the problem downstream by upsizing conduits. Lumped models with relatively large subcatchments provide a bottom up view of the system. The modeler is confronted with the problem of determining how much natural flow constraint occurs in the upstream system, particularly if no large storm events are available for calibration. Underestimating the natural flow restraint in the local system can cause projects to be proposed for trunk lines that are not really flooding, which would not reduce the risk of flooding in the local system unless the local system is also replaced.

\section{Acknowledgments}

The HOSTSU Project is managed by Tammy Cleys of BES and Brain Hemphill of Carollo Engineers. Primary modeling support for the project is being provided by David Crawford of Crawford Engineering Associates. Additional modeling support is being provided by Laura Dutt of Carollo Engineers and Paula Arsenault of PMA Engineering.

The model definition, virtual raingage, and GIS modeling tools were developed under the joint effort of the BES GIS and Modeling Group. The work of the following individuals is gratefully acknowledged: Virgil Adderley, Mark Liebe, Arnel Mandilag, Tim Kurtz, and David Argast.

\section{References}

Sullivan, Stark, \& Holladay Basins Pre-design - Problem Characterization Report, Carollo Engineers, October 1999. 
U.S. EPA Storm Water Management Model, SWMM Version 4.05 (Portland Version) User's Manual, August 1992.

City of Portland, Public Facilities Plan, July 1999, Environmental Services, City of Portland. 